\title{
Development a Basic Model of the Innovation System
}

\author{
Sergey Mikhailovich Vasin ${ }^{1} \&$ Leyla Ayvarovna Gamidullaeva ${ }^{1}$ \\ ${ }^{1}$ Department of Economics and Management, Penza State University, Penza, Russia \\ Correspondence: Sergey Mikhailovich Vasin, Department of Economics and Management, Penza State \\ University, Penza, 440026, Russia. Tel: 8-909-317-33-66. E-mail: pspu-met@mail.ru
}

Received: June 4, 2015 Accepted: July 10, 2015 Online Published: July 24, 2015

doi:10.5539/res.v7n11p175

URL: http://dx.doi.org/10.5539/res.v7n11p175

\begin{abstract}
The authors developed a structural basic model of innovation system, which feature is the presence a subsystem of knowledge development. Its mechanisms will ensure the immanence of innovative activity in the economic structure of enterprises, guarantee the continuity of the economic cycle of innovation and institutional aid. The basic characteristics inherent to this model and the fundamental principles of its construction have been offered. It has been revealed that for the management of innovation system it is necessary to make changes in the established socio-economic relations, because innovative development is limited by them.
\end{abstract}

Keywords: innovation system, model of control system, innovative development

\section{Introduction}

Russia in modern conditions is in the process of finding the optimal strategy for socio-economic development of the country. Neither the government nor the society is satisfied with inertial prosperity provided by world prices for commodities. Russia's WTO accession significantly increased risks and uncertainty about the future development of the domestic economy. Thus, in today's globalizing world, the construction of innovation systems (IS) becomes a necessity, as evidenced by both scientists and statesmen. Despite the successful implementation of IS models in many foreign countries, in Russia the problem is becoming more and more urgent.

\section{Literature Review}

Nelson (1993), Freeman (1995) and Lundvall (2000) can be considered as the founder of the theory of national innovation systems. Framework conditions of the development of a new theory include linear model of innovation; works by V. L. Makarov and other scientists appealing to the knowledge-based society (Makarov, 2003); study of the triple helix (Etzkowitz, 2010). These authors and their followers, including a large number of Russian scientists (Gohberg, 2003; Granberg \& Valentey, 2006; Zhiharev, 2011; Ivanova, 2005; Postalyuk, 2006; Tatarkin, 2005, etc.) have contributed to the defining, structuring of the innovative system, the development of methodological research platform for innovation processes, as well as specific mechanisms and tools to increase the effectiveness of innovation.

\section{Theoretical framework}

The issue of creating a basic model of the innovation system, the use of which would ensure the effectiveness of its implementation in the country's economy remains unsolved. Under the basic innovation system we mean a system that includes all the necessary basic elements and links between them to ensure obtaining the synergistic effects. Taking into account the fact that the implementation of the concept of the innovation system into the economy of some countries, including Russia, does not give a positive result, we concluded that solution of the problem lies in ensuring coherence of the structural elements.

In this context, the aim of this article is to identify the disadvantages of traditional approaches to the construction of the innovation system and to develop the base model for the introduction into the Russian economy.

\section{Method}

As a methodological basis of research at different stages, depending on the nature of tasks, the method of system analysis was used. The methods of analysis and synthesis, induction and deduction, comparative, historical, retrospective analysis and benchmarking, as well as the interviewing techniques were applied in the course of the study. 
In our opinion, the answer to the question of how to build an innovative system which models, mechanisms and instruments should be developed to start the innovation process depends on the methodological approach. The representatives of the national science support the view that the conceptual framework of the economic theory must be radically reformed. In this regard, a set of paradigms of economic theory in general consisting of neoclassical, institutional and evolutionary paradigms, at the macro level has been supplemented by the system paradigm. Among the variety of economic systems the study of innovation systems becomes increasingly important. Foreign researchers believe that the innovative system can be viewed from different perspectives (Carlsson et al., 2002). First of all, they speak of the innovation system in its territorial manifestation. The boundaries of the innovation system, as a rule, coincide with national or regional boundaries.

In our study we will adhere to the viewpoint of S. Y. Glazyev, considering an innovative system as a result of the interaction of three main elements: the innovator, the organization and the external environment (Glazyev, 1993). Thus, the first element includes an individual, production factors involved in the development of innovations and personnel. This item is a part of a vast system - namely organization, which is a part of the environment, emerging from the interaction of various factors - political, economic, environmental, social. Innovation can be viewed as a set of innovative processes aimed at the creation and diffusion of innovations. Determination of the innovation process helps to reveal the mechanisms of its implementation into the economic system.

In our study, we suggest to understand under the innovative process a set of relations for the use of innovations in order to obtain a synergistic effect. Type of the innovation process depends on the economic system, stage, level and scope of its development, as well as the type of the innovation.

The essence and the content of innovation processes should be examined not only as a continuous developing process, but also as their discrete stages and cycles. Analysis of works by E. Mansfield, E. Ames, E. Trine, M.P. Postalyuk, and others (Mansfield, 1970; Postalyuk, 2006 etc.), considering the structure of the innovation cycle, led to the conclusion that they lack the most important stage - a creative one. In this context, we offer the following structure phases of the innovation cycle:

- basic research focused on the creation of new scientific knowledge;

- creative phase within which innovative ideas arise as a result of creative activity or previously made fundamental discoveries or applied research;

- phase of the invention within which the technical solutions are developed for the use of innovative ideas as well as their institutional support in the process of applied research and as a result there is obtaining relevant intellectual property rights;

- phase of development and experimentation which ends up in obtaining a prototype and an experimental sample of innovation;

- phase of real innovation, including experimental production and product's market testing;

- phase of the market launch and dissemination of innovation;

- phase of transformation of innovation into an economic tradition that turns into a base for a new innovation process.

It is noteworthy that M. P. Postalyuk, offering to highlight that "the creative phase of the emergence of innovative ideas in the process of fundamental and applied researches, discoveries, inventions generated by economic tradition as a genetic resource, human needs and the progress of knowledge" (Postalyuk, 2006), gives it a different wide content.

We insist on the separation of phase of basic research and creative phase. The last one means a continuous monitoring of new knowledge in the company`s scope of interests where primary ideas arise as the result of the process of detection of any conflict or reaction drawn up in a specific form by an economic subject due to the absence of anything required. That conflict can be, for example, the mismatch between the effectiveness of existing technologies and the changed conditions of their use in the framework of a specific enterprise.

Under the innovative economic cycle we shall understand the process, including economic relations from the inception period of innovative ideas until the moment of their transformation into innovation (commercialization of innovation).

Consequently, the source of the implementation of the innovation process is an innovative idea and the resource is the system of established socio-economic relations.

At the same time the enterprise acts as the backbone of innovative relations, where an innovative idea takes 
specific forms in terms of making it available to the sphere of consumption.

The structure of the subjects of innovation relationship is dynamic and contradictory. Contradictions mainly lay in a plane of the subjects purposes. So, for the research organizations the main aim is to develop fundamental innovative ideas.

For organizations that focus primarily on applied research, the goal is the embodiment of innovative ideas into particular innovations. Commercial entrepreneurs are largely driven by profits. And the innovative activity serves as a means to achieve these goals that can attain synergetic and communicative effect.

Objectively the problem of innovation, especially its role in the development of economic systems remains a subject for scientific debate in the economic theory that as practice shows indicates an increasing role of intellectual property and intellectual labor.

Crucial in the decision-making process of a manager, which provides economic development, is considered the intellectual potential, not the costs of labor.

It is important to consider that innovation is a material basis to increase the efficiency of the economy as well as the growth in production volumes. Using the new features can enhance the quality and competitiveness of products and reduce their costs. Innovation activity provides an impetus to self-development, imbalance and ensures the activity of economic mechanism.

Without the use of innovation it becomes impossible to increase the level of productive forces and, consequently, the creation of conditions for the development of production, i.e., innovative economic activity is an essential objective element of the economic system, which forms the mechanism of self-development of the economy, increasing its synergistic effects.

Therefore, innovation should be an integral part of the internal economic mechanism of functioning of the enterprises, ensuring the creation of a competitive environment and to achieve equilibrium in the economy.

An important question is what kinds of innovations are introduced into the economy. G. Mensch, for example, offers to divide all the innovations into three types: basic, which create new products (services) and therefore play a crucial role in the development of the economic system; improving, developing basic innovations; and pseudo-innovations that make minor changes in the technology itself (Zhiharev, 2011).

It is noteworthy that not only individual firms specialize in different types of innovation, but also the countries as a whole which are able to develop innovations to varying degrees.

Justification of the basic model of the innovation system. As noted earlier, innovative system is the result of the interaction of the innovator, the company and the external environment.

The innovation system at all levels should consist of the system itself, represented by the structural elements and the relationships between them, as well as the external environment, including near and distant surroundings.

It should be noted that the innovation system functions on the one hand as the rapidly changing system in time, but on the other hand, as stably existing set of subjects and objects of innovation.

E. Kuznetsov believes that adequate representation of the innovation activities is a network model, arguing that "modern innovative system offers a new organizational structure, which includes a number of special models (structures), for example, a network model ..." (Kuznetsov, 2000).

Regarding the dynamic aspect of networked relationship between the participants of innovation - it is linked to the fact that in the framework of these relations the innovative processes are constantly carried out and they are related to the development and implementation of innovations that are targeted.

A key element of any IS is a private company, where production of innovation should become a routine. This activity should be done everywhere, and also be a part of all units of the economic system, to become its supporting structure.

To do this innovative economic activitie should be directly integrated in the economic system of enterprises.

Continuing arguments on the conceptual aspects of the nature and content of the innovation in the economic systems at different levels, we note that new knowledge can be created periodically by the fundamental science, but due to the lack of mechanisms for their development in the innovation system, they cause the resistance of the system itself, therefore these inventions remain at the initial stage without leading to the emergence of innovation.

In our opinion, this situation is due to the fact that the concept of IS contains a gap in providing a creative phase 
of the innovation process; its realization requires the presence of creative potential of employees of enterprises and the innovative thinking. Therefore it is necessary, first of all, the massive involvement of all employees in the innovation process, regardless of their level of hierarchy in the enterprise.

It also requires an open information system in which the latest achievements in the field of basic research will be shared by all sectors of society and permeate all parts of the economy, and thus of the innovation system itself, being thereby the basis for creative and inventive activity of an innovator as a key element of the entire innovation system.

Management innovation systems should be based on a corporate approach that assumes involving the whole society in the process of governance and management.

In addition, this approach means that the system of management of complex systems, especially management, focused on innovative development must be integrated into the control system itself so that the control mechanisms are consistent with the mechanisms and patterns of self-organization and self-government.

Construction of the basic innovative system should also be based on existing trends in modern development paradigm of the innovation system as a whole.

In the former development paradigm the main emphasis is on the fact that innovations as integrated technologies emerge, mainly in large companies, or in a long chain of creating added value, where participants of the chain are linked by rather rigid relations.

The modern paradigm is based on the fact that the main innovations appear in the form of new products and production is based on the use of modular high-end technologies, often developed in new small and medium-sized firms, based on a single technology.

The old paradigm was based on the concept of the closed architecture of the final product, which means that the product is considered as a system, the relations and the elements of which are not standardized at the level of inter-firm cooperation, whereby it is the result of a complex assembly.

In the twenty-first century the concept of the open architecture of the product emerged, and the product is seen as a set of standardized modules and, accordingly, relations between them.

Thus, the standards are accepted by market participants. In this regard, the development and introduction of new standards of architecture can only be possible as a result of radical innovation.

And for incremental innovation, respectively, there is a significant narrowing of the field of activity.

In addition, the loss of elasticity of demand which is becoming characteristic of the modern market also reduces the need for incremental process innovations to maintain a competitive position in the market.

There are the following directions in formation of the shifts in innovative activity:

-from the development of process innovations to product ones;

-from the incremental product innovations to radical innovations;

-from engineering innovations to innovations, based on the use of basic knowledge and similar applications, and others.

These trends dictate the need to change the strategy of behavior of firms in the innovation system.

Increased risks of innovative activity dictate the need for specialization of firms focused on mastering the sole market niche.

In other words, contrary to popular belief, not diversification of activities, but specialization of innovative economic processes is typical for describing the behavior of economic agents in the innovation system.

Directions of activity which are not primary, may be implemented in cooperation with external partners, or can be outsourced.

This increases the importance of the organization of mutually beneficial cooperation and interaction.

Besides, according to the former paradigm the main source of new knowledge for the company were its own units, but now there is a shift towards the effective connection of external and internal sources of knowledge.

The company has to constantly monitor the process of creating new knowledge through the public sector of science.

A strong connection of science and private companies is considered reasonably necessary because it provides a permanent unimpeded crossflow of knowledge from basic research to practical inventions and economic activity. 
In our opinion the problem of connectivity of the system to ensure the continuous implementation of the innovation cycle has not been adequately reflected in current research.

Classical structure of the innovation system at different spatial levels (national, regional, etc.) usually includes the following subsystems: knowledge production, mechanisms of knowledge transfer and implementation of knowledge.

In our opinion, this system lacks a very important element of the development of knowledge. We have already noted the importance of the creative phase of the innovation cycle, when an innovative idea based on fundamental research is developed and then embodied in the form of new products, services and processes.

Consequently, the subsystem of mechanisms of knowledge development must be present in the innovation system that will allow to realize the innovative potential of the domestic companies through the formation of the primary ideas - the driving force in the development of innovative systems, indicating the need for new innovations in the company.

Building a market way of innovation based on the primary idea, seems necessary to assess the functionality of the object taking into account the relationship of innovation with the functions performed by other elements.

This process must include professionally-oriented creative thinking and a qualification of subjects of innovation.

All in all, for effective exploring fundamental knowledge in the country and in the world we need to create an effective system of its development within enterprises followed by the introduction in the production process.

We believe that as the mechanisms for the implementation of this system can be of service such organizational forms of cooperation and integration of staff as quality circles, contributing to the formation of so-called "innovation climate" in the organization, able to create conditions for the effective use of the intellectual potential of employees.

Innovation and invention can be considered as another mechanism in the enterprises when special working groups are in charge of carrying out a continuous search in improving management processes, rationalization of labor, economy of resources, identification of existing contradictions, prompting the creation of the primary innovative ideas, etc.

Also, for better dissemination and development of basic knowledge it is possible to use the mechanisms of government subsidies to the best job placement of graduates of higher education institutions in small and medium-sized technological companies.

\section{Results}

Thus, the model of the innovation system must take the following form (Fig. 1). 


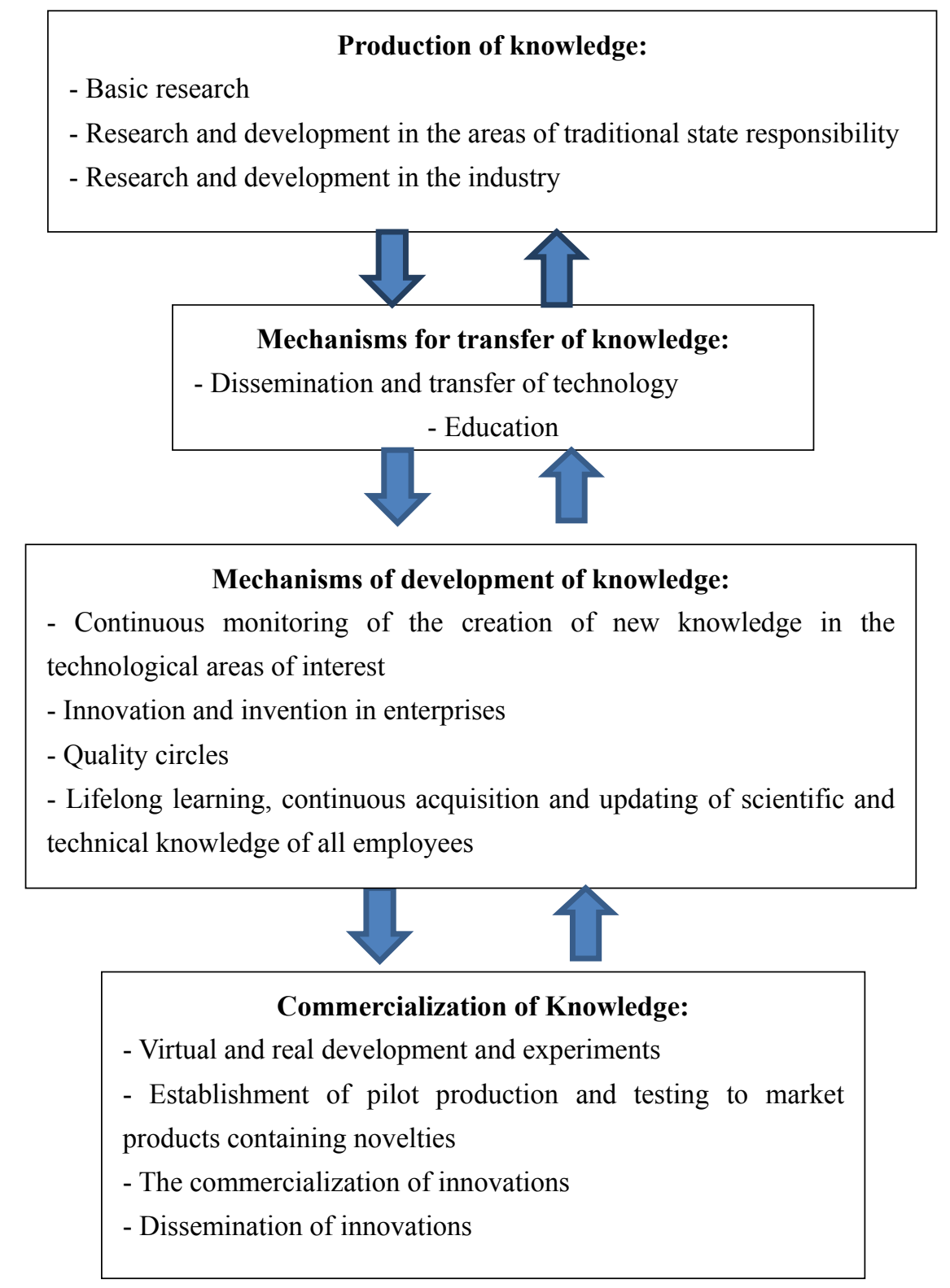

Figure 1. The model of the basic innovation system (developed by the authors)

The most important elements of any innovation system, as already noted, are the companies of various types.

Companies create new knowledge in the course of current operations due to the efforts of its employees, managers and owners through practical training, as well as by specialized research works and projects (Coriat \& Weinstein, 2002).

Thus, as shown in studies of many scientists (Hamel, 2002), the nature and behavior of the companies varies considerably in different countries regions, cultures, and in different socio-economic conditions.

The characteristics of the basic model of the innovation system. The effectiveness of the knowledge development carried out by companies in IS will depend on the characteristics related to how different they acquire, generate, distribute and use the new knowledge necessary for innovation.

Filling the existing gap in the theoretical structure of the innovation system, we proceed directly to the consideration of essential characteristics of the developed model in basic innovation system.

These characteristics take into account the identified trends of changes in innovation paradigm in modern conditions, as well as recognition of the need for the presence in the innovation system of the subsystem of 
knowledge development with following from it new economic relations.

The first characteristic of the IS, which should be intrinsically inherent in it is the presence of high level interaction between owners and managers with employees, partners and other organizations to acquire new knowledge and skills, as well as the presence of opportunities for integration of new fundamental knowledge (discoveries, inventions) in the company.

This naturally determines the ability of companies in the development of knowledge and in the commercialization of innovations.

The second characteristic of the IS is employee participation in the process of creative problem solving and the creation of new products, processes and services in the development of new knowledge.

The understanding that management should be distributed among different groups of employees in different degrees is crucial.

Companies often organize this activity only by the efforts of the management. This approach appears fundamentally wrong, because in this type of activity mainly skilled workers should be involved, regardless of their level of hierarchy.

The third characteristic of the IS is the network nature of the relationship between companies and the organization of interaction between them. Cooperation and exchange of information between institutions should not be limited by any authoritarian boundaries. The relationship between the two companies should be built on trust and on the basis of long-term strategic cooperation.

The relationship between the two companies should be built on trust and on the basis of long-term strategic cooperation. The distribution of powers within the organization should not be limited.

It should be a constructive cooperation with competitors on training, standard setting, etc., and it is supposed to be the interaction, based on the competitive addition rather than on substitution.

The fourth characteristic is a high level of development and use of knowledge generated by the formal system of education and science. This is due to the close interaction between the public sector of science and education and companies. The high level of development and use of knowledge is largely determined by the speed of finding and using new knowledge, the ability to determine the timeliness and appropriateness of its own research and development. Such processes require a highly integrated joint training of researchers, joint management of research projects, hiring professionals from the public sector of science and education. This process involves feedback, namely the hiring of employees of the companies in the research organizations.

Thus, companies within the framework of innovation system will not be limited in their development by their abilities according to prevailing trajectories.

The fifth characteristic of IS is the high level of regulation of the activity of subjects in innovation system, which can be carried by the state and non-state associations, consortia, integrated business groups etc.

It reduces the risks incurred by all the participants by means of their distribution. The innovative system should be self-organizing subject-controlled system to ensure the transition from the unpredictable behavior of the system to its directed movement along the desired invariant trajectory. To manage the innovation system it is necessary to make changes in the sphere of existing socio-economic relations, as they have limited innovative development.

This requires to reform the system of relations between science, education and business, regulation of enterprise activity, also to make changes in the internal structure of the companies (the transition to organic forms, network and matrix management structure), the ownership structure of the labor market, in the culture of government and labor relations etc.

Construction of the innovation system should be based on the following principles.

Firstly, on the principle of coherence of the innovation system. It is necessary to keep ties between the individual phases of the economic cycle of innovation in the IS, which must begin with the fundamental research carried out in the priority directions for the state and development of the world economy in general. Secondly, a comprehensive and integrated nature of IS i.e. innovation activity must permeate all parts of the economic system that the latter was transformed thus into the innovation. Thirdly, systematic and continuous nature of the organization of the innovation process. The characteristic principle of stimulating the growth of innovative activity is that all subjects of IS must carry out a systematical and continuous search and prediction of hidden dangers and new opportunities. Fourth, focus on the strategic development goals of the state and trends of global 
development in order to avoid crises of technological structures, etc.

\section{Conclusions}

Thus, in the result of the theoretical study we complemented the innovative structure of the business cycle by including a creative phase. It has been found that the innovative economic activities can be regarded as an objective element of the economic system, which creates a mechanism of self-development of the economy, therefore the conclusion is drawn that innovative activities should be is inscribed in mechanism of management of the enterprise. It has been proved that the IS management should be built into the control system itself, so that the control mechanisms are supposed to be connected and coordinated with the mechanisms and patterns of self-organization and self-government. It has been proposed to complement the structural model of the innovation system by a subsystem of development of knowledge, the mechanisms which will ensure the continuity of the economic cycle of innovation and institutional support. The basic characteristics inherent to the basic model of the innovation system and inherent principles have been formulated. It has been revealed that for the management system of innovation it is necessary to make changes in the prevailing socio-economic relations, as they have limited innovative development.

\section{References}

Asaul, A. (2008). Modernization of the economy based on technological innovation (p. 606). St. Petersburg.

Carlsson, B. et al. (2002). Innovation Systems: Analytical and Methodological Issue. Research Policy, 31, 233-245. http://dx.doi.org/10.1016/S0048-7333(01)00138-X

Cooke, P. (2001). Regional innovation systems, clusters, and the knowledge economy. Industrial and Corporate Change, 10 (4), 945-974. http://dx.doi.org/10.1093/icc/10.4.945

Coriat, B., \& Weinstein, O. (2002). Organizations, Firms and Institutions in the Generation of Innovation. Research Policy, 31, 273-290. http://dx.doi.org/10.1016/S0048-7333(01)00141-X

Edquist, C. (2004). Systems of Innovation-A Critical Review of The State of the Art. In J. Fagerberg, D. Mowery, \& R. Nelson (Eds.), Handbook of Innovation. Oxford: Oxford University Press.

Etzkowitz, H. (2010). Triple Helix. Universities—state-enterprise. In Innovation in action (p. 238). Tomsk.

Freeman, C. (1995). The National System of Innovation in Historical Perspective. Cambridge Journal of Economics, 19, 5-24.

Gamidullaeva, L. A. (2014). Problems and prospects of the Russia's economy modernization. In Fundamental Research (pp. 11-19).

Glazyev, S. Yu. (1993). The theory of long-term technical and economic development (p. 310). Moscow.

Godin, B. (2010). National Innovation System: A Note on the Origins of a Concept. Working Paper, Project on the Intellectual History of Innovation.

Golichenko, O. G. (2011). The main factors of development of the national innovation system (p. 634). M: Nauka.

Hamel, G. (2002). Leading the Revolution. Harvard Business School Press.

Hochberg, L. (2003). National Innovation System. Questions of economy, 3, 26-44.

Ivanova, N. (2005). The innovation system of Russia in the global context. World Economy and International Relations, 7, 32-53.

Kuznetsov, E. (2000). Innovations and their role in economic development. (p. 142). SPb.

Lundvall, B. A. (2000). Systems of Innovation: Growth, Competitiveness and Employment. An Elgar Reference Collection. Cheltenham, UK: Edward Elgar Publishing.

Makarov, V. L. (2003). Economy of Knowledge: Lessons for Russia. Herald of the RAS, 5, 450-456.

Mansfield, E. (1970). Economics of scientific and technical progress (p. 171). Moscow.

Nelson, R. (1993). National Innovation Systems: A Comparative Analysis. New York: Oxford University Press.

Nill, J., \& Kemp, R. (2009). Evolutionary approaches for sustainable innovation policies. Research Policy, 38, 668-680. http://dx.doi.org/10.1016/j.respol.2009.01.011

Postalyuk, M. P. (2006). Innovative relations in the economic system: Theoretical and methodological aspect (p. 339). Kazan. 
Schumpeter, J. A. (1942). Capitalism, Socialism and Democracy. New York: Harper \& Row.

Shinn, T. (2002). The Triple Helix and New Production of Knowledge Prepackaged Thinking in Science and Technology. Social Studies of Science, 32, 599-614. http://dx.doi.org/10.1177/030631202128967271

Vasin, S. M., \& Gamidullaeva, L. A. (2013). Improving management of business incubator as a socio-economic system (p. 218). Penza State University.

Wieczorek, A. J. et al. (2012). Contemporary Innovation Policy and Instruments: Challenges and Implications. Working Paper Series Paper. Innovation Studies Utrecht (ISU).

Zhiharev, K. L. (2011). Methodology of management development of regional innovation system (p. 438). Moscow.

\section{Copyrights}

Copyright for this article is retained by the author(s), with first publication rights granted to the journal.

This is an open-access article distributed under the terms and conditions of the Creative Commons Attribution license (http://creativecommons.org/licenses/by/3.0/). 